\title{
Ionospheric response at conjugate locations during the 7-8 September 2017 geomagnetic storm over the Europe-African longitude sector
}

\author{
John Bosco Habarulema ${ }^{1,2}$, Zama T Katamzi-Joseph ${ }^{1,2}$, Dalia Burešová ${ }^{3}$, \\ Rendani Nndanganeni ${ }^{1}$, Tshimangadzo Matamba ${ }^{1}$, Mpho Tshisaphungo $^{1}$, \\ Stephan Buchert ${ }^{4}$, Michael Kosch ${ }^{1}$, Stefan Lotz ${ }^{1}$, Pierre Cilliers ${ }^{1}$ and \\ Ayman Mahrous ${ }^{5}$

\footnotetext{
${ }^{1}$ South African National Space Agency (SANSA), P.O Box 32, Hermanus 7200, South Africa.

${ }^{2}$ Department of Physics and Electronics, Rhodes University, 6140 Makhanda, South Africa.

${ }^{3}$ Institute of Atmospheric Physics CAS, Bocni II 1401, 14131 Prague 4, Czech Republic.

${ }^{4}$ Swedish Institute of Space Physics, Uppsala University, Uppsala, Sweden.

Alexandria, Egypt.
} \\ ${ }^{5}$ Institute of Basic and Applied Science, Egypt-Japan University of Science and Technology (E-JUST),
}

\section{Key Points:}

- The storm led to TEC enhancement in the southern hemisphere mid-latitude region that was at least twice that in the northern hemisphere on 08 September 2017.

- Physical processes related to low latitude origin, thermospheric composition changes and large scale TIDs all had an influence on the observed profound positive ionospheric storm effects

- Ionospheric bottomside and topside/plasmasphere contributions to TEC were different in both hemispheres during the storm main phase. 


\section{Abstract}

This paper focuses on unique aspects of the ionospheric response at conjugate locations over Europe and South Africa during the 07-08 September 2017 geomagnetic storm including the role of the bottomside and topside ionosphere and plasmasphere in influencing electron density changes. Analysis of total electron content (TEC) on 07 September 2017 shows that for a pair of geomagnetically conjugate locations, positive storm effect was observed reaching about $65 \%$ when benchmarked on the monthly median TEC variability in the northern hemisphere, while the southern hemisphere remained within the quiet time variability threshold of $\pm 40 \%$. Over the investigated locations, the southern hemisphere mid-latitudes showed positive TEC deviations that were in most cases twice the comparative response level in the northern hemisphere on the 08 September 2017. During the storm main phase on 08 September 2017, we have obtained an interesting result of ionosonde maximum electron density of the F2 layer and TEC derived from Global Navigation Satellite System (GNSS) observations showing different ionospheric responses over the same mid-latitude location in the northern hemisphere. In situ electron density measurements from SWARM satellite aided by bottomside ionosonde derived TEC up to the maximum height of the F2 layer (hmF2) revealed that the bottomside and topside ionosphere as well as plasmasphere electron content contributions to overall GNSS derived TEC were different in both hemispheres especially for 08 September 2017 during the storm main phase. The differences in hemispheric response at conjugate locations and on a regional scale have been explained in terms of seasonal influence on the background electron density coupled with the presence of large scale traveling ionospheric disturbances and low latitude associated processes. The major highlight of this study is the simultaneous confirmation of most of the previously observed features and their underlying physical mechanisms during geomagnetic storms through a multi-dataset examination of hemispheric differences.

\section{Introduction}

It is well established that dynamic and electrodynamic processes associated with interactions between the solar wind, magnetosphere and ionosphere primarily control the ionospheric behavior during geomagnetic storms [e.g., Kelley et al., 1979; Prölss, 1993; Scherliess and Fejer, 1997; Buonsanto, 1999; Danilov, 2001; Prölss, 2004; Huang, 2008, and references therein]. Additionally and over many decades, studies have shown that 
global and regional ionospheric responses to occurrence of geomagnetic storms significantly vary with a number of factors such as local time at storm onset, location, seasons and sometimes the intensity as well as the duration of the geomagnetic disturbances [e.g., Prölss, 1993; Buonsanto, 1999; Danilov, 2001; Buresova et al., 2014]. The commonly observed responses due to geomagnetic storms are enhancement and depletion in electron density or total electron content of the ionosphere, which are usually referred to as positive and negative ionospheric storm effects, respectively [e.g., Prölss, 1993; Mendillo, 2006; Buresova et al., 2014; Vijaya Lekshmi et al., 2011; Matamba et al., 2015]. Irrespective of the ionospheric parameterization used, there are cases where no significant deviation (from the background electron density) is observed to 'qualify' as negative or positive ionospheric storm effects during storm conditions [e.g., Vijaya Lekshmi et al., 2011; Matamba et al., 2015]. Thus, there are varying physical mechanisms used to explain different observations [e.g., Prölss, 1993, 1995; Buonsanto, 1999]. It is now accepted that the composition changes within the thermosphere are largely responsible for negative storm effects [e.g., Prölss, 1993; Buonsanto, 1999; Danilov, 2001], while the interpretation of positive storm effects involves various mechanisms such as increased or enhanced vertical $\mathbf{E} \times \mathbf{B}$ drift, occurrence of atmospheric gravity waves and prompt penetrating electric fields [e.g., Prölss, 1993; Tsurutani et al., 2004; Vijaya Lekshmi et al., 2011; Ding et al., 2007; Ngwira et al., 2019, and references therein]. Inevitably, similar latitude regions in different hemispheres could present different responses due to the physical mechanisms that may be dominant in each hemisphere. Consequently, each storm period may have its particular characteristics and influence on the ionospheric electron density response in high, low and mid latitude regions [e.g., Yizengaw et al., 2005]. Recently, the solar and geophysical conditions during/around 05-14 September 2017 have received considerable attention for a number of reasons including (but not limited to) the period being associated with: producing most of the solar flares in solar cycles 24 [e.g., Curto et al., 2018; Mosna et al., 2020] with some flare activity leading to significant ionospheric electron density and TEC increase [Yasyukevich et al., 2018; Li et al., 2018; Mosna et al., 2020] in the sun-lit longitude regions, geomagnetic storm that led to occurrence of plasma bubbles that were observed over mid latitudes [Aa et al., 2019], existence of long duration positive storm effects in some longitudes such as the Asian-Australian sector [Lei et al., 2018], and the different response in nature of the Earth's magnetosphere and ionosphere to the development and occurrence of the two consecutive storms [e.g., Jimoh et al., 
2019; Blagoveshchensky et al., 2019]. The interesting nature of this storm period led to a dedicated Special Section Issue in AGU's Journal of Space Weather under the theme "Space Weather Events of 4-10 September 2017". This storm period has therefore been studied extensively. Nevertheless, there are some ionospheric storm related features and peculiarities that have not yet been reported. This paper focuses on unique aspects of the ionospheric response at the conjugate locations over Europe and South Africa during the 07-08 September 2017 geomagnetic storm including the role of the bottomside and topside ionosphere and plasmasphere in influencing electron density changes. On 07 September 2017, analyzed TEC over selected locations in the mid-latitude northern hemisphere indicated a positive storm effect while their conjugate counterparts in South Africa did not show significant deviations from monthly median TEC, which is considered as the representation of the background ionospheric conditions. While both mid-latitudes showed positive storm effect during the storm main phase on 08 September 2017, the response (in terms of magnitude) in the southern hemisphere was at-least twice that of the northern hemisphere and for an extended period of time (over 8 hours compared to less than 2 hours for northern hemisphere). We have used ionosonde, GNSS (specifically GPS) and SWARM satellite data to study the evolution, nature of the response, and physical mechanisms that played dominant roles in influencing mid latitude ionospheric density and TEC changes during the storm period of 07-08 September 2017 in the two hemispheres.

\section{Data sources}

We have utilized both ground-based and satellite observations to describe the temporal, spatial and altitudinal response of the ionosphere during the selected storm period of 07-08 September 2017. The data sources used are:

1. Ionosonde data: This provides the bottomside ionospheric parameters. In this study, the ionosonde was the source of the critical frequency of the F2 layer (foF2) which reveals the F2 region response to the occurrence of the geomagnetic storm. This data also provided the electron density values at different altitudes, which were used to derive the bottomside contribution of TEC up to the peak height of the F2 layer (hmF2) to analyze the stormtime response of the ionosphere at conjugate locations. Data from the South African ionosonde network for locations Grahamstown, GR13L $\left(33.3^{\circ} \mathrm{S}, 26.5^{\circ} \mathrm{E}\right)$, Her- 
manus, HE13N $\left(34.4^{\circ} \mathrm{S}, 19.2^{\circ} \mathrm{E}\right)$, Louisvale, LV12P $\left(28.5^{\circ} \mathrm{S}, 21.2^{\circ} \mathrm{E}\right)$ and Madimbo, MU12K $\left(22.4^{\circ} \mathrm{S}, 30.9^{\circ} \mathrm{E}\right)$ represented the southern hemisphere, while Pruhonice, PQ052 $\left(50.0^{\circ} \mathrm{N}, 14.6^{\circ} \mathrm{E}\right)$ ionosonde was used to study the northern hemispheric mid-latitude response. These are the ionosonde locations where we had access to all data records to allow us to check the ionograms for the correctness in the autoscaling software. Manually scaling of some ionograms was performed where necessary as autoscaling confidence levels are sometimes degraded during geomagnetically disturbed conditions. This manifests in terms of the autoscaling software "failing" to follow the ionogram traces which can result into incorrect values of the ionospheric parameters [e.g., Huang and Reinisch, 1996; Habarulema and Carelse, 2016].

2. SWARM satellite data: The SWARM satellite mission consists of three identical satellites with an inclination of $87.75^{\circ}$ at altitudes of $\sim 460 \mathrm{~km}(\mathrm{~A}$ and $\mathrm{C})$ and $500 \mathrm{~km}$ (B), and are thus well positioned for topside ionosphere studies. They provide among others, in situ electron density and total electron content at these altitudes as a function of latitude, and therefore give simultaneous information about the topside behavior (and by proxy, the plasmasphere contribution to TEC) and the extent of the equatorial ionization anomaly (EIA) development or absence during investigated periods. In this study, SWARM data were used to compare its electron density with bottomside electron content and GPS TEC at nearly conjugate locations in southern and northern hemisphere mid-latitudes.

3. GPS TEC data: This is the basis for providing continuous ionospheric TEC response with respect to latitude and diurnally during the entire period of study and hence revealing different observations peculiar to each latitude region in both hemispheres. Vertical TEC was derived from GPS observations using an algorithm that assumes an ionospheric thin shell height at $350 \mathrm{~km}$. To minimize errors related to multipaths while retaining significant data coverage (as our investigation also covered regions with little or no ground-based GNSS receivers), an elevation threshold of 15 degrees was used. Within the longitude sector covering $20^{\circ} \mathrm{E}-40^{\circ} \mathrm{E}$, and latitude range of $40^{\circ} \mathrm{S}-70^{\circ} \mathrm{N}, 2$-dimensional diurnal vertical TEC maps are produced for the 6-9 September 2017. Furthermore, within the same spatial resolutions, TEC data were detrended using a fourth order polynomial function based on individual GPS satellite's observations and TEC perturbation (referred to as 
$\triangle \mathrm{TEC}$ ) plots as a function of latitude and time were generated during 6-9 September 2017. For both TEC and $\triangle$ TEC plots, data were binned within 3 minutes by $2^{\circ}$ (time/latitude) and average TEC or $\triangle \mathrm{TEC}$ plotted for each bin. This reveals regions and times of TEC enhancements and/or depletions on a spatial scale within the considered longitude sector during the analyzed period.

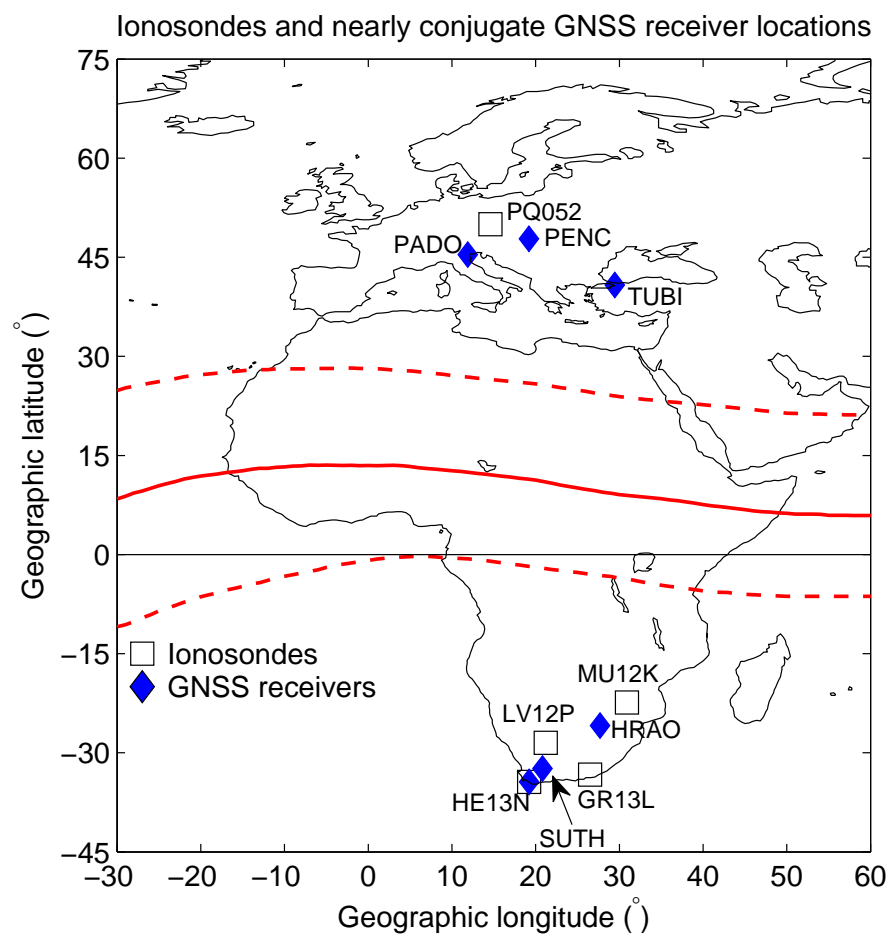

Figure 1. Map showing locations of ionosondes and some GNSS receivers which were used in conjugacy analysis. Over Hermanus $\left(34.42^{\circ} \mathrm{S}, 19.22^{\circ} \mathrm{E}\right)$, ionosonde (HE13N) and GNSS receiver (HNUS) are co-located. The red solid line indicates the geomagnetic equator. Additional details about the locations can be found in Table 1.

Figure 1 is the map showing the location of ionosondes and nearly geomagnetically conjugate GNSS receivers used in Europe and South Africa. For clarity, not all GNSS receivers used in the study for generating 2-dimensional TEC and $\triangle$ TEC maps are indicated on this map. While some of the receivers have the capability of providing observations from more than one GNSS constellation, we have specifically used the Global Positioning System (GPS) data in this study. 


\subsection{Solar wind and geomagnetic activity conditions}

In general, the solar and geomagnetic activity conditions for 04-11 September 2017 have been described as complex largely due to the occurrence of multiple solar flares of different classes [e.g., Curto et al., 2018; Yasyukevich et al., 2018; Mosna et al., 2020] and storm related activity that led to two consecutive Dst minima separated by about 13 hours on the same day [e.g., Lei et al., 2018; Aa et al., 2019; Blagoveshchensky et al., 2019]. Figure 2 shows changes in (a) solar wind velocity, $V_{s w}(\mathrm{~m} / \mathrm{s})$ and $B_{z}$ component of the interplanetary magnetic field, IMF $B_{z}(\mathrm{nT})$, (b) Auroral electrojet, AE (nT) index and SYM-H (nT) index equivalent to high resolution Dst index [Wanliss and Showalter, 2006], and (c) the interplanetary electric field, IEF $=-V_{x} \times B_{z}(\mathrm{mV} / \mathrm{m})$; during 06-11 September 2017. Two X-class solar flares occurred on 06 September 2017. The X2.2 and X9.3 solar flares peaked at 0910 UT and 1202 UT respectively. The accompanying coronal mass ejection (CME) led to the geomagnetic storm conditions of 07-08 September 2017 with SYM-H minima values of $-146 \mathrm{nT}$ and $-115 \mathrm{nT}$ at about $0108 \mathrm{UT}$ and $1356 \mathrm{UT}$ on 08 September 2017. The vertical dashed red lines indicate the shocks' arrival times on the Earth's magnetosphere at about 2343 UT and 2300 UT on 06 and 07 September 2017 respectively. The $V_{s w}$ showed two instances of sudden increase from about $400 \mathrm{~km} / \mathrm{s}$ to $600 \mathrm{~km} / \mathrm{s}$ (at 2343 UT on 06 September) and at 2300 UT on 07 September 2017, $V_{s w}$ reached just over $700 \mathrm{~km} / \mathrm{s}$ before continuing a steady increase attaining a value of $800 \mathrm{~km} / \mathrm{s}$ at $0200 \mathrm{UT}$ on 08 September 2017. Before the end of the first storm, an additional CME led to another onset of the main-phase at 1135 UT on 08 September 2017 reaching a mimimum SYM-H of -115 nT (1356 UT) and thereafter, the geomagnetic storm conditions began a gradual recovery.

Between $\sim 0400-1200$ UT, the IMF $B_{z}$ was mostly southward on 07 September 2017 with some noticeable periods of northward turning. The IMF $B_{z}$ reached the minimum value of $-32.1 \mathrm{nT}$ and corresponding increase in IEF of $21.6 \mathrm{mV} / \mathrm{m}$ at $2335 \mathrm{UT}$ on 07 September 2017. The last substantial IMF $B_{z}$ negative excursion reaching $-16 \mathrm{nT}$ was recorded at 1200 UT on 08 September 2017.

\section{Results and discussions}

Figure 3 shows TEC changes for the period of 06-09 September 2017 within $40^{\circ} \mathrm{S}$ $70^{\circ} \mathrm{N}$ and $20-40^{\circ} \mathrm{E}$ geographic latitude/longitude coverage. The solid black horizon- 

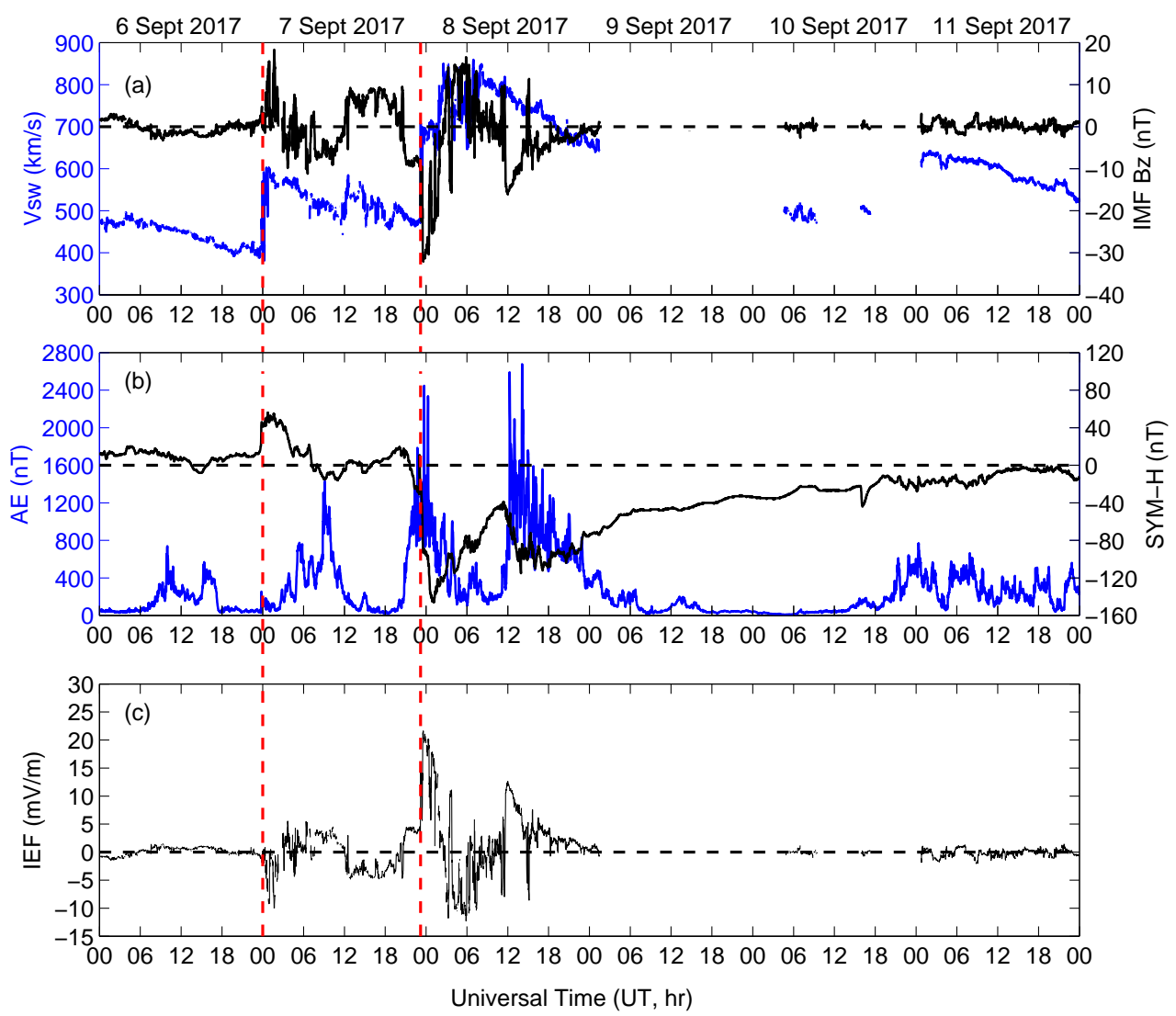

Figure 2. Geomagnetic and interplanetary conditions during 6-11 September 2017. The vertical red dashed lines show the arrival times of CME shocks on the Earth's magnetosphere at 2343 UT and 2300 UT on 06 and 07 September respectively.

tal line at $10^{\circ} \mathrm{N}$ geographic latitude approximates the geomagnetic equator. Figure 3 is generated by considering TEC for satellites above $15^{\circ}$ elevation and binning data into $2^{\circ}$ latitude by 3 minutes.

The black vertical straight lines on Figure 3(a) show the occurrence time of the two solar flares X2.2 and X9.3 at 0910 UT and 1158 UT respectively on the 06 September 2017 [e.g., Curto et al., 2018; Yasyukevich et al., 2018; Li et al., 2018; Mosna et al., 2020]. As indicated in Figure 2, the first sudden storm commencement occurred on 06 September 2017 at 2343 UT, while both main and recovery phases were on 08 September 2017. In response to the storm activity, Figure 3(c) shows increased TEC in both hemispheres on 08 September 2017 compared to the rest of the days during this storm period. The 

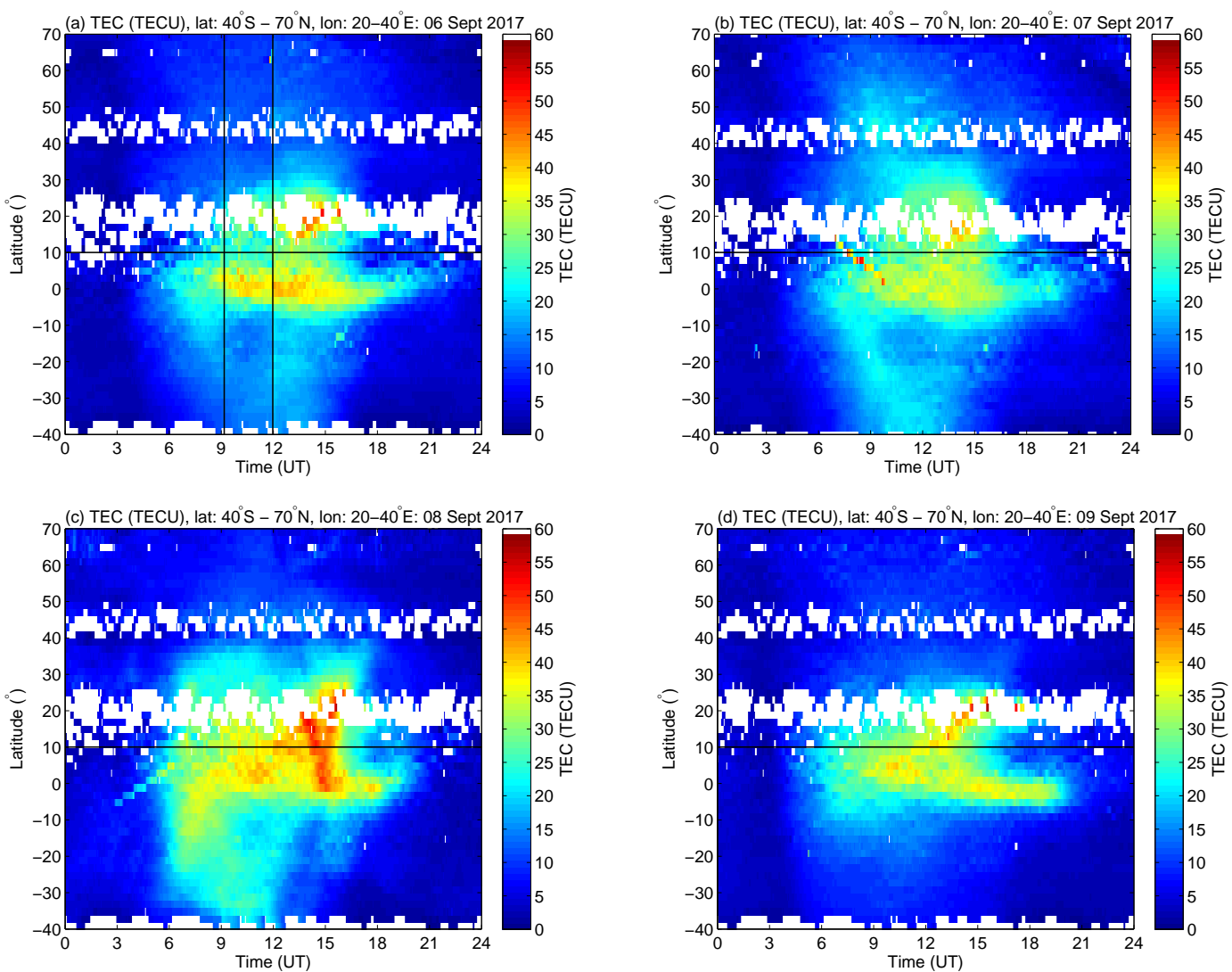

Figure 3. TEC (TECU) for the period 06-09 September 2017 within $40^{\circ} \mathrm{S}-70^{\circ} \mathrm{N}$ and $20-40^{\circ} \mathrm{E}$ geographic latitude/longitude coverage. The black solid line at $10^{\circ} \mathrm{N}$ geographic latitude approximates the location of the geomagnetic equator. The white spaces in the northern hemisphere indicates data gaps.

TEC enhancement with an extended latitude coverage can be seen to be more strong in the southern hemisphere.

\subsection{TEC response at conjugate locations}

For a detailed and quantitative measure of the ionospheric response, Figure 4 shows the TEC deviations from monthly medians (expressed in percentages) for the three pairs of nearly geomagnetically conjugate GNSS locations. The conjugacy information was determined based on the altitude-adjusted corrected geomagnetic coordinates system [Baker and Wing, 1989; Shepherd, 2014]. The geographic and geomagnetic information of the respective conjugate receiver pairs are provided in Table 1 . With a latitudinal difference of atmost $1^{\circ}$ between the locations within all GNSS receiver pairs, the geomagnetic lat- 
itudes are close enough to be considered conjugate. The percentage deviations are computed using

$$
\Delta Y=\left(\frac{Y-Y_{m}}{Y_{m}}\right) \times 100
$$

where $Y$ and $Y_{m}$ represents daily TEC and the corresponding monthly median values respectively. The horizontal black dashed lines in Figure 4 show the quiet time threshold of $\pm 40 \%$ [e.g., Matamba et al., 2015], implying that within this range, normal background ionospheric TEC behavior is expected. This simple procedure is used to identify the observed ionospheric storm effects during geomagnetically disturbed conditions.

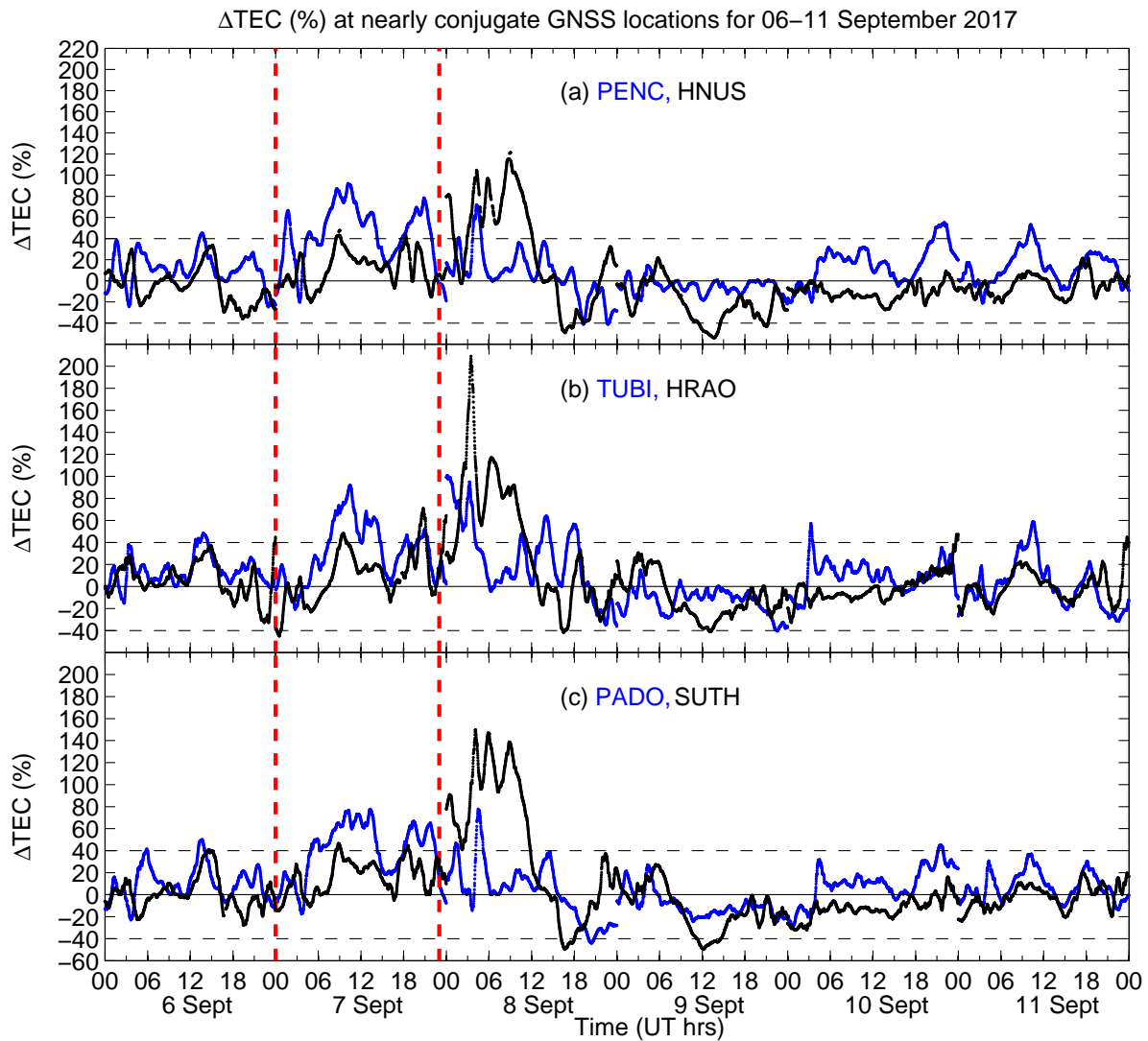

Figure 4. Percentage deviations of TEC from monthly median values over GNSS conjugate locations in the Euro-African region. Geographic and geomagnetic coordinates of the GNSS locations are shown in Table 1. 
Table 1. Geographic and geomagnetic coordinates of conjugate GNSS locations used in this study. NGI and IGS represent National Geospatial Information and International GNSS Service respectively.

\begin{tabular}{|c|c|c|c|c|c|c|}
\hline \multirow[t]{2}{*}{ Location/country } & \multirow[t]{2}{*}{ Code } & \multirow[t]{2}{*}{ Grouping } & \multicolumn{2}{|c|}{ Geographic coordinates } & \multicolumn{2}{|c|}{ Geomagnetic coordinates } \\
\hline & & & Latitude & Longitude & Latitude & Longitude \\
\hline Hermanus (South Africa) & HNUS & NGI & -34.42 & 19.22 & -42.34 & 82.14 \\
\hline FOMI Satellite Geodetic & PENC & IGS & 47.79 & 19.28 & 43.03 & 93.9 \\
\hline \multicolumn{7}{|l|}{ Observatory (Hungary) } \\
\hline Hartebeesthoek RAO (South Africa) & HRAO & IGS & -25.89 & 27.69 & -36.32 & 94.69 \\
\hline Tubitak (Turkey) & TUBI & IGS & 40.79 & 29.45 & 35.07 & 101.91 \\
\hline Sutherland (South Africa) & SUTH & IGS & -32.38 & 20.81 & -41.09 & 84.76 \\
\hline University of Padova (Italy) & PADO & IGS & 45.41 & 11.89 & 40.08 & 86.94 \\
\hline
\end{tabular}

There are two main observations from Figure 4 during the 07-08 September 2017. On 07 September, we observe a positive $\triangle$ TEC deviation of $30-50 \%$ from the quiet time threshold of $40 \%$ over the northern hemisphere for a period of about 8 hours (0700-1500 UT). $\triangle$ TEC variability for the southern hemisphere locations largely remained within the normal quiet time range of $\pm 40 \%$. This is consistent with thermospheric mass density results derived from the Gravity Recovery and Climate Experiment (GRACE) observations at $350 \mathrm{~km}$ altitude which showed an increase in the northern hemisphere [Yuan et al., 2019]. However, SWARM-A thermospheric mass density at $450 \mathrm{~km}$ altitude showed a slight enhancement in the southern hemisphere with no corresponding observation in the northern hemisphere during daytime. In essence, while at different altitudes, GRACE and SWARM-A thermospheric mass density observations provide contradicting results, which were partly attributed to the dominant coupling processes between the ionosphere and thermosphere at GRACE altitudes [Yuan et al., 2019]. In the context of $\triangle$ TEC variability on 07 September 2017, this may point to different contributions at different altitudes, an issue that will be investigated further using ionosonde and satellite data. In the study by Yuan et al. [2019], day-time consideration of thermospheric mass density was centered at about 1000 local solar time (LST) and 0930 LST for SWARM A and GRACE respectively, while corresponding night time analysis is at 2200 LST (SWARM) and 2130 
LST (GRACE). Given that the neutral mass is much greater than electrons' mass, descrepancies related to response time lag are expected and it is therefore interesting to note that their respective densities show some similarities.

The second distinct observation is the positive storm effect observed in both northern and southern hemispheres during the storm main phase on 08 September 2017. However, the southern hemisphere observations show long-lasting positive storm effect during the period of 0300-1200 UT. Within this time interval, northern hemisphere locations show the positive storm effect not exceeding 1.5 hours compared to 9 hours for the southern hemisphere. The maximum deviation from monthly median reached just over $200 \%$ for $\mathrm{HRAO}\left(36^{\circ} \mathrm{S}\right.$, magnetic) while its conjugate location TUBI $\left(35^{\circ} \mathrm{N}\right.$, magnetic) had a corresponding deviation of $90 \%$. Maximum deviation $(160 \%)$ for SUTH $\left(41^{\circ} \mathrm{S}\right.$, magnetic) is also twice the deviation value for its conjugate location $\mathrm{PADO}\left(40^{\circ} \mathrm{N}\right.$, magnetic). The difference in deviation between HNUS and PENC magnetic latitudes of $42^{\circ} \mathrm{S}$ and $43^{\circ} \mathrm{N}$ respectively is just over $30 \%$ at about 1100 UT. Both GRACE and SWARM-A thermospheric mass densities on 08 September 2017 showed enhancements during day and night-times in both hemispheres. However SWARM-A results exhibited significantly increased thermospheric mass density in the southern hemisphere from 0000-1200 UT [Yuan et al., 2019] which is exactly the same time duration when $\triangle$ TEC values are higher over South Africa compared to Europe. For GRACE, the response is stronger in the northern hemisphere than southern hemisphere.

To establish the relative contribution to vertical TEC at varying altitudes, Figure 5(a)-(b) shows the ionosonde TEC (in black dots) over Hermanus $\left(34.4^{\circ} \mathrm{S}, 19.2^{\circ} \mathrm{E}\right.$; $42.3^{\circ} \mathrm{S}$ geomagnetic) and Pruhonice $\left(50.0^{\circ} \mathrm{N}, 14.6^{\circ} \mathrm{E} ; 45.7^{\circ} \mathrm{N}\right.$ geomagnetic) for $07-08$ September 2017. Ionosonde TEC (hereafter referred to as ITEC) is essentially the bottomside TEC, computed as follows;

$$
\text { ITEC }=\int_{\sim 90 \mathrm{~km}}^{\mathrm{hmF} 2} N_{e} d x
$$

where $N_{e}$ is the electron density per $m^{3}$, and $d x$ is the variable of integration (step size) along a vertical path between about $90 \mathrm{~km}$ and the height of the peak electron density (hmF2).

ITEC is derived up to hmF2 peak to eliminate the topside contribution. Due to its relatively smaller values, ITEC in Figure 5(a)-(b) has been scaled by a factor of 2 for easy visibility and comparability with GPS derived TEC. GPS TEC for 07-08 Septem- 

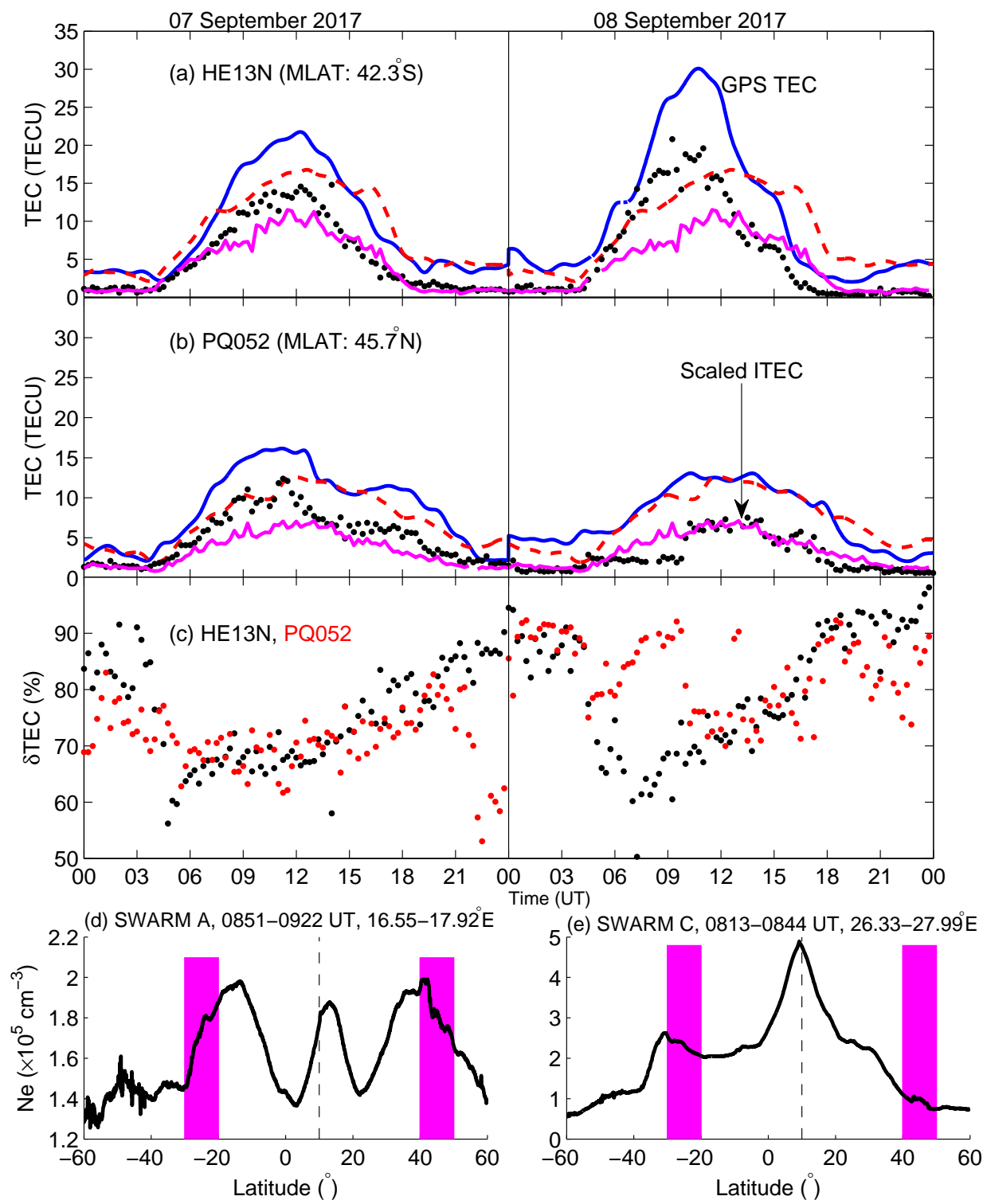

Figure 5. GPS TEC (blue curve) and scaled ITEC by a factor of two (black dots) for (a) HE13N, (b) PQ052 on 7-8 September 2017, (c) deviation (\%) between GPS TEC and ITEC up to hmF2 peak. The red dashed and solid magenta lines in (a)-(b) show GPS TEC and scaled ITEC (by a factor of 2) for the most quiet day of 26 September 2017. SWARM electron density changes during 0851-0922 UT $\left(17^{\circ} \mathrm{E}\right)$ and 0813-0844 UT $\left(27^{\circ} \mathrm{E}\right)$ are plotted in (d) and (e) for 07 and 08 September 2017 respectively. 
ber 2017 is plotted (solid blue lines) for the two locations for easy reference and direct comparison. Included in Figure 5(a)-(b) is also TEC for the most quiet day (26 September 2017) of the month plotted in red dashed and solid magenta lines for GPS TEC and ITEC respectively. In Figure 5(a), there is increased bottomside ITEC (compared to 26 September) on 08 September 2017 until 1300 UT which agrees well with results presented in Figure 4. However, ITEC appears to be more sensitive to storm induced processes such as thermospheric composition changes as it shows negative storm behavior (just after 1300 UT) about 2 hours earlier than GPS TEC, a result confirmed later with foF2 analysis. Basing the analysis on the quiet time reference of 26 September 2017, we can deduce different bottomside response for HE13N and PQ052 between 0600-1000 UT on 08 September 2017. Storm-time ITEC is enhanced over HE13N while it reduced over PQ052 during this time interval. While GPS TEC is clearly enhanced (see blue curve) compared to the quiet-time reference (red dashed line) over HE13N, both disturbed and quiet-time values for PQ052 are relatively similar during 0600-1000 UT. This is a direct evidence that bottomside ionosphere contributed differently in the two hemispheres. To quantify the bottomside contribution, Figure 5(c) shows the relative deviation ( $\delta$ TEC) between GPS TEC and ITEC derived up to hmF2 altitude, normalized to GPS TEC and expressed as a percentage for HE13N (black dots) and PQ052 (red dots). Here, actual ITEC values (and not scaled ITEC) were used to derive $\delta$ TEC. The normalization is important to have a scale free quantity that provides the realistic behavior of the bottomside response/contribution which is location specific. Small percentage deviation values indicate that GPS TEC and ITEC are close to each other and the latter could have made a significant contribution. Figure 5(c) reveals that the combination of topside and plasmasphere contributed over 75-90\% of the overall TEC on 08 September 2017 over PQ052 compared to $60-70 \%$ for HE13N during 0400-0900 UT. Generally, the bottomside contribution is greater during the day-time as opposed to nighttime. This is consistent with related previous studies. For example, global climatological studies have reported plasmaspheric contribution reaching $25-45 \%$ (daytime) and 50-60\% (nighttime) to GPS TEC on the basis of COSMIC data with integration altitude set at $700 \mathrm{~km}$ [Cherniak et al., 2012], and 10\% (daytime) and 60\% (nighttime) when JASON altimeter data at $1335 \mathrm{~km}$ altitude was used as a reference to GPS TEC [Yizengaw et al., 2008]. Between 0600-1200 UT on 07 September 2017, there are instances where the bottomside contribution is greater over PQ052 than at HE13N, although other results are comparable. However, Figure 5(c) 
clearly shows high bottomside ITEC over PQ052 between 1500-1900 UT, a consistent result with the thermospheric mass density results at GRACE altitude of $350 \mathrm{~km}$ in the northern hemisphere [Yuan et al., 2019]. Plotted in Figure 5(d)-(e) is the in situ electron density from SWARM A and C satellites when the passes are either close to these ionosonde locations or within the longitude range of our analysis. SWARM A and C have data during 0851-0922 UT and 0813-0844 UT along the $17^{\circ} \mathrm{E}$ and $27^{\circ} \mathrm{E}$ on 07 and 08 September 2017, respectively. In Figure 5(d)-(e), the magenta shaded regions are equidistant $\left(30-40^{\circ}\right)$ from the geomagnetic equator (black vertical dashed lines). On the 07 September 2017, SWARM A observations in Figure 5(d) show slighly higher values in the northern hemisphere, while topside electron density values are enhanced in the southern hemisphere on 08 September 2017. A peak in electron density can be seen in Figure 5(e) at about $40^{\circ} \mathrm{S}$ magnetic latitude which directly provides evidence of equatorial ionization anomaly expansion to southern hemisphere mid-latitudes as observed from topside. SWARM electron density observations are consistent with GPS TEC in both hemispheres. A recent investigation utilizing a number of Low Earth Orbit satellite data (including SWARM) reported increased topside TEC for the main phase of the storm on 08 September 2017 as well as hemispheric asymmetry during both day and nighttime [Jimoh et al., 2019].

In addition to high levels of bottomside contribution to TEC increases in the southern hemisphere on 08 September 2017, there could have been more effective thermosphereionosphere coupling process in the southern hemisphere such as the presence of atmospheric gravity waves which are well known to contribute to electron density or TEC enhancement [e.g., Prölss, 1993]. In this regard, Figure 6 shows $\triangle$ TEC (TECU) for 0609 September 2017 within latitude and longitude ranges of $40^{\circ} \mathrm{S}-70^{\circ} \mathrm{N}$ and $20-40^{\circ} \mathrm{E}$ respectively. The solid vertical lines indicate the time occurrence of solar flares on 06 September 2017. The $\triangle \mathrm{TEC}$ is computed by fitting a fourth order polynomial to each satellite's TEC data followed by differencing the TEC and fitted data. Interestingly, Figure 6(a) reveals insights of the solar flare effects on TEC that were not directly observable from TEC data in Figure 3(a). This is best illustrated by the black straight line at around 1200 UT (Figure 6(a)) showing $\triangle$ TEC enhancement spanning the entire considered latitude range $40^{\circ} \mathrm{S}-70^{\circ} \mathrm{N}$ within the $20-40^{\circ} \mathrm{E}$ longitude sector. This is due to the X9.3 solar flare which started at 1158 UT on 06 September 2017 [Curto et al., 2018]. The first X2.2 solar flare at 0910 UT on 06 September 2017 did not generate clearly visible changes in TEC as seen in Figure 6(a). The global ionospheric response (including using data 

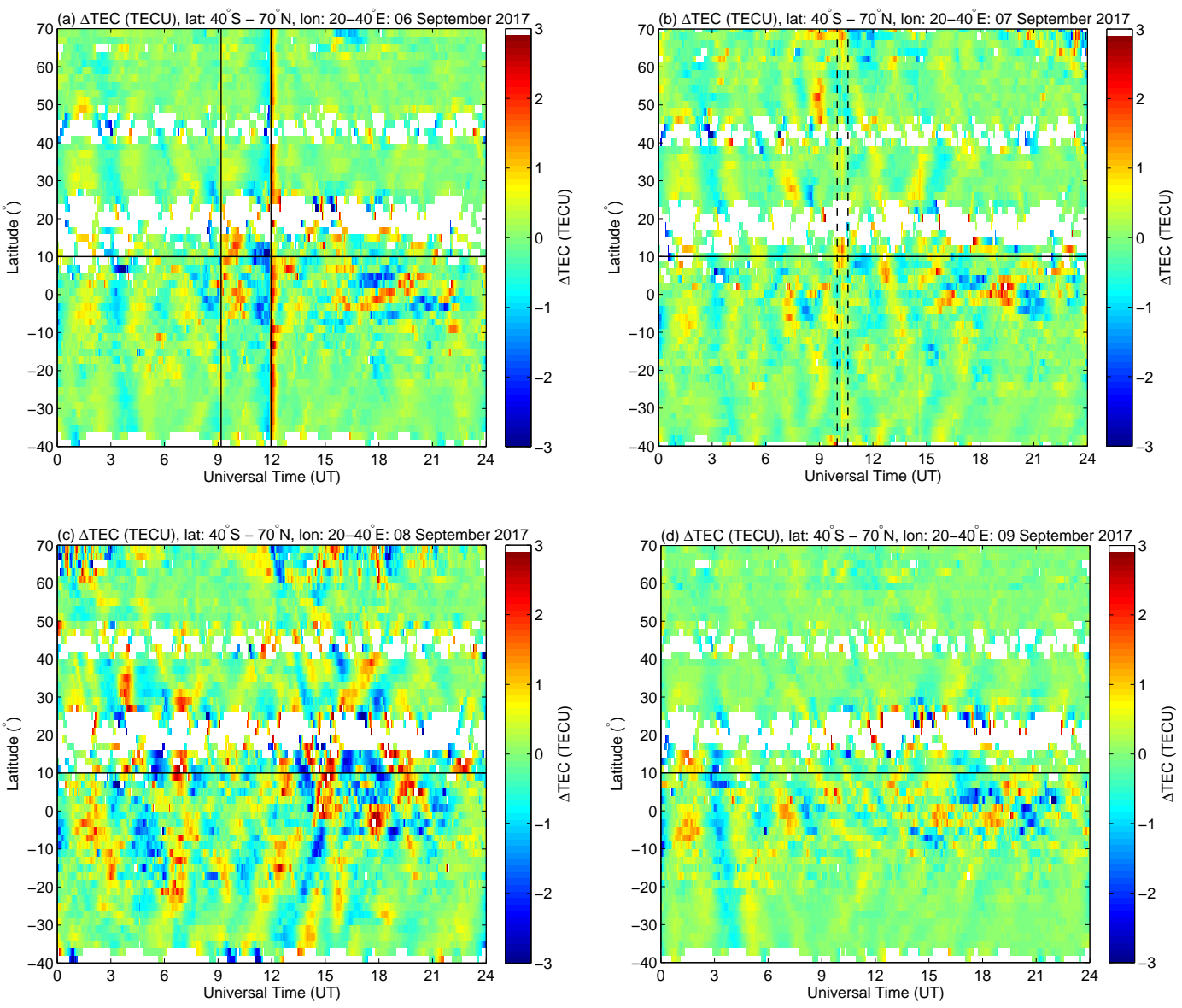

Figure 6. $\Delta$ TEC changes for 06-09 September 2017 within latitude and longitude ranges of $40^{\circ} \mathrm{S}-70^{\circ} \mathrm{N}$ and $20-40^{\circ} \mathrm{E}$ respectively.

over Europe and South Africa) to solar flares on 06 September 2017 has been reported in Li et al. [2018] highlighting an increase in TEC and foF2 for the X9.3 flare occurrence which peaked at 1202 UT compared to the less intense X2.2 that had its peak at 0910 UT. Therefore, Figure 6(a) demonstrates the importance of utilizing different parameterization when studying different ionospheric phenomena. For example, the quiet time threshold of $\pm 40 \%$ does not reveal the effect of solar flare on TEC while data detrending shows the clear significant increase on 06 September 2017 at about 1200 UT. While an increase in TEC is observed starting at 1200 UT in Figure 4, the variability dominantly remained within the quiet-time threshold range of $\pm 40 \%$.

Another important observation in Figure 6(b), is the simultaneous TEC enhancement at around 1010 UT (indicated within two dashed vertical black lines) in both hemispheres on 07 September 2017. Conjugacy analysis (Figure 4) shows that this is the ap- 
proximate time when TEC was slighly enhanced above the background levels in the southern hemisphere while there is a clear TEC increase in the northern hemisphere. In addition to M7.3 solar flare that peaked at 1015 UT [Mosna et al., 2020], this can also be linked to the increased auroral activity on 07 September 2017 when we see high AE values reaching $1430 \mathrm{nT}$ at $0907 \mathrm{UT}$ (Figure 2(b)) and the negative polarity of IMF Bz. These conditions are favorable for prompt penetrating electric fields which lead to increased electron density or TEC at all latitudes at the same local time, a consistent feature in Figure 6(b) at about 1000 UT. Increased TEC has also been reported in high latitudes on 07 September 2017 [Blagoveshchensky and Sergeeva, 2019] and during the nighttime between 07-08 September 2017. What appears to be an effect of the X1.3 solar flare which peaked at 1436 UT can faintly be seen in Figure 6(b) on 07 September 2017 at latitudes $10-40^{\circ} \mathrm{S}$. The ionospheric electron density on 07 September 2017 was under the influence of multiple external sources including solar flares and storm induced processes. The effect of the X1.3 solar flare at 1436 UT on 07 September 2017 was clearly seen in the Very Low Frequency band using Marion island $\left(46.87^{\circ} \mathrm{S}, 37.87^{\circ} \mathrm{E}\right)$ observations [Lotz and Clilverd, 2019].

Returning to the possible presence of atmospheric gravity waves (AGWs) during 06-09 September 2017, Figure 6(c) shows traveling ionospheric disturbances (TIDs) which were predominantly propagating from the southern to the northern hemisphere. The TID activity is more pronounced in the southern than in the northern hemisphere especially on the 08 September 2017. Large scale TIDs are known to contribute to positive storm effects [e.g., Prölss, 1993] and their observations during periods of geomagnetic storms in relation to enhanced ionospheric electron density and/or TEC have been widely reported [e.g., Ding et al., 2007; Borries et al., 2016; Zakharenkova et al., 2016; Ngwira et al., 2019, and references therein].

\subsection{Regional Ionospheric response}

Understanding the physical mechanisms for the TEC response during the 07-08 September 2017 storm period requires the use of different independent datasets. Figure 7 shows the critical frequency of the F2 layer (foF 2 ) and TEC variability expressed as percentages with respect to monthly median values during 06-11 September 2017 over/near South Africa and Czech Republic ionosonde locations. The percentage deviations were computed using equation (1), where in this case, $Y$ and $Y_{m}$ represent daily foF2 (TEC) and 
the corresponding monthly median values respectively. The solid magenta and black dashed lines in Figure 7 show the quiet time thresholds of $\pm 20 \%$ and $\pm 40 \%$ for foF 2 and TEC respectively. These threshold ranges of $-20 \% \leq \triangle f \circ F 2 \leq 20 \%$ and $-40 \% \leq \triangle T E C \leq$ $40 \%$ are widely used in literature [e.g., Danilov, 2001; Buresova et al., 2014; Matamba et al., 2015] to represent the background variations while studying ionospheric storm effects in presence of geomagnetic disturbances.

Table 2. Geographic and geomagnetic coordinates of ionosonde locations used in this study. SANSA $=$ South African National Space Agency, ASCZ= Academy of Sciences of the Czech Republic.

Location/country

URSI Code Grouping Geographic coordinates Geomagnetic coordinates

\begin{tabular}{lcccccc} 
& & & Latitude & Longitude & Latitude & Longitude \\
\hline Hermanus (South Africa) & HE13N & SANSA & -34.4 & 19.2 & -42.34 & 82.14 \\
Grahamstown (South Africa) & GR13L & SANSA & -33.3 & 26.5 & -41.95 & 90.17 \\
Louisvale (South Africa) & LV12P & SANSA & -28.5 & 21.2 & -38.31 & 86.87 \\
Madimbo (South Africa) & MU12K & SANSA & -22.4 & 30.9 & -33.19 & 99.24 \\
Pruhonice (Czech Republic) & PQ052 & ASCZ & 50.0 & 14.6 & 45.66 & 90.42 \\
\hline
\end{tabular}

For TEC variations, GNSS receivers are colocated with ionosondes at Hermanus, HE13N $\left(34.42^{\circ} \mathrm{S}, 19.22^{\circ} \mathrm{E}\right)$ and Grahamstown, GR13L $\left(33.3^{\circ} \mathrm{S}, 26.5^{\circ} \mathrm{E}\right)$. The GNSS receiver codes for Hermanus and Grahamstown are HNUS and GRHM respectively. For Louisvale, LV12P $\left(28.50^{\circ} \mathrm{S}, 21.20^{\circ} \mathrm{E}\right)$ and Madimbo, MU12K $\left(22.39^{\circ} \mathrm{S}, 30.88^{\circ} \mathrm{E}\right)$ ionosonde stations, the nearest GNSS receivers are located at Upington, UPTA $\left(28.40^{\circ} \mathrm{S}, 21.25^{\circ} \mathrm{E}\right)$ and Thohoyandou, TDOU $\left(23.08^{\circ} \mathrm{S}, 30.38^{\circ} \mathrm{E}\right)$ which are approximately 10 and $90 \mathrm{~km}$ away, respectively. For the northern hemisphere mid-latitude region, ionosonde and TEC data are from Pruhonice, PQ052 $\left(50.0^{\circ} \mathrm{N}, 14.6^{\circ} \mathrm{E}\right)$ and the nearby receiver Ondrejov, GOPE $\left(49.9^{\circ} \mathrm{N}, 14.8^{\circ} \mathrm{E}\right)$, respectively, which are about $18 \mathrm{~km}$ apart. Table 2 shows the geographic and geomagnetic coordinates of the ionosonde locations. The underlying idea for the simultaneous analysis of ionosonde foF2 and TEC data at co-located sites is to investigate whether these datasets exhibited an identical response to the geomagnetic activity. Short durations of increased foF2 are observed over GR13L and MU12K at around 1000 UT on 07 September 2017, with clear increased foF2 around 1800-1900 UT for all 


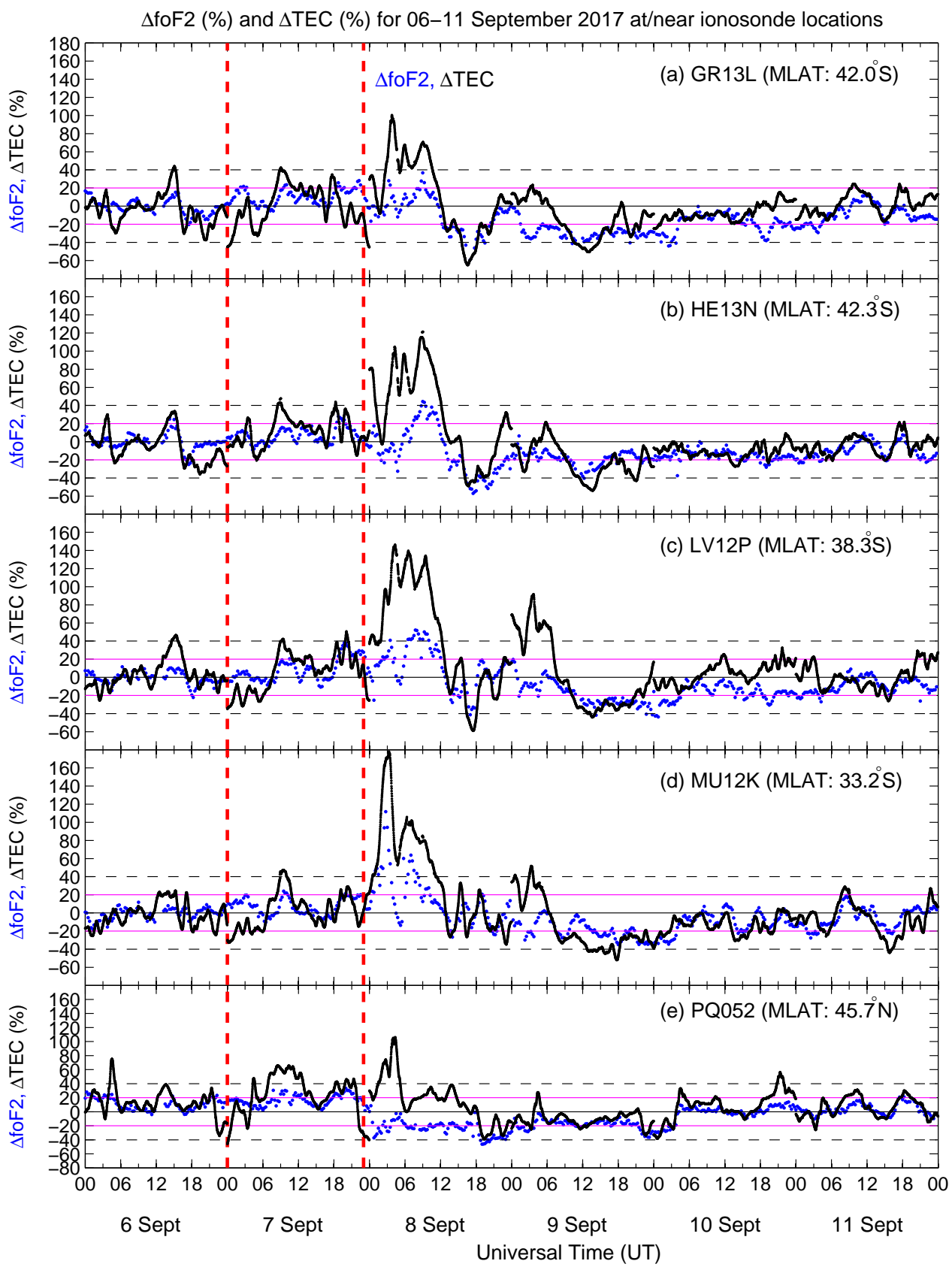

Figure 7. Variability of foF 2 and TEC expressed as a percentage to respectively monthly median values over South African ionosonde ((a)-(d)) locations and (e) Pruhonice, Czech Republic during 06-11 September 2017. The red vertical dashed lines show the shocks arrival times at 2343 UT (06 September) and 2300 UT (07 September). 
South African ionosonde data. On the contrary, PQ052 ionosonde data showed enhanced foF2 for almost the whole of 07 September 2017, a result that was also recently reported by Mosna et al. [2020] and confirmed by GOPE TEC data for a large part of the day (0600-1300 UT). Both foF2 and TEC over South Africa show positive storm effect on 08 September 2017 from around 0300-0900 UT (with TEC increase extending until 1200 UT) which largely coincided with the storm main phase (as shown in Figure 2), followed by a negative storm phase, with exception of MU12K where decreased foF2 is only seen on 09 September during similar times as at the other locations. Considering MU12K's geomagnetic latitude location $\left(33.2^{\circ} \mathrm{S}\right)$, we can conclude from Figure $3(\mathrm{c})$ that it could have been under the influence of the EIA during the whole of 08 September 2017 which will be further investigated later. Increase in foF 2 reached $40 \%$ for HE13N and GR13L with LV12P's highest value at just over 50\% between 0600-1200 UT, while MU12K which is towards the low latitude region registered the highest electron density increase reaching $60 \%$ during this time period. In addition, an even higher increase in foF 2 was registered over MU12K during the pre-dawn hours at around $0300 \mathrm{UT}$, and this is well corroborated with the TEC response as shown in Figure 7(d). On the other hand, positive storm effect from TEC data over GOPE $\left(49.9^{\circ} \mathrm{N}, 14.8^{\circ} \mathrm{E}\right)$ is observed during $\sim 0300-$ 0500 UT, while Pruhonice $\left(50.0^{\circ} \mathrm{N}, 14.6^{\circ} \mathrm{E}\right)$ shows decreased foF 2 below the background for the entire 08 September 2017 reaching maximum negative deviation of $40 \%$. Ionospheric positive response for HE13N is just over $40 \%$ at 1200 UT at the time when PQ052 recorded a negative storm effect and yet these locations are nearly geomagnetically conjugate. The maximum $\triangle$ TEC reached over GOPE at $\sim 0400 \mathrm{UT}$ is comparable with the corresponding value at HNUS, although the latter indicates higher values before and after this time. The key observation here is the different ionospheric responses over PQ052 from two datasets (ionosonde foF2 and GPS TEC), suggesting different physical mechanisms at different altitudes. One of the possible sources for positive storm effect as shown by GPS TEC is the electron content from the topside and plasmasphere as has been clearly shown in Figure 5(c). During the recovery phase, a negative ionospheric storm effect was largely evident (especially from ionosonde data) on 08 September from 1000 UT and 09 September 2017 starting at 0900 UT until 0600 UT on 10 September 2017. Over Europe, results of maximum electron concentration of the ionospheric $\mathrm{F} 2$ layer (NmF2) increase and decrease on 07 and 08 September respectively for Ebre $\left(40.8^{\circ} \mathrm{N}, 0.5^{\circ} \mathrm{E}\right)$ have been reported [Cander, 2018]. Thermospheric $\mathrm{O} / \mathrm{N}_{2}$ ratio results from the Global Ultravio- 
let Imager (GUVI) onboard TIMED satellite published in Imtiaz et al. [2020] show enhanced and depleted values over the analyzed locations in the southern and northern hemispheres respectively on 08 September 2017. Temporal evolution of TEC and electron density dynamics indicate that the southern hemisphere mid-latitude region was under the influence of competing/opposing processes arising from the EIA expansion and neutral composition changes as a result of heated lower parts of the thermosphere in auroral and/or high latitudes [Buonsanto, 1999; Yizengaw et al., 2005]. At the same time, large scale TIDs are known to contribute to short-lived positive storm effect [Prölss, 1993] and can be seen to be present on 08 September 2017. Therefore EIA expansion and TIDs were responsible for the positive storm effect until 1200 UT on 08 September 2017, while the equatorward movement of depleted $\mathrm{O} / \mathrm{N}_{2}$ ratio that is redistributed by neutral winds led to the decreased TEC and foF2 observed after 1200-1300 UT on 08 September and 09 September 2017. Figure 3(d) shows that all mid-latitude regions experienced depleted TEC changes, which is well reflected in $\Delta$ foF2 showing negative storm effect on 09 September 2017 (Figure 7). In the summer hemisphere, the combined effect of background thermospheric neutral gas composition and storm-related circulation can lead to short-lived positive storm effect [Prölss, 2004], although the thermospheric composition changes originating from auroral and high latitudes play a major role leading to negative storm effects. This is the probable mechanism for the observed depleted TEC in the northern hemisphere on 08 September 2017 and for the rest of the storm duration. Indeed, the $\mathrm{O} / \mathrm{N}_{2}$ ratio shows a decrease over the northern hemisphere mid-latitude region on 08 September 2017 [Imtiaz et al., 2020].

Therefore, from Figure 7, we observe strong TEC enhancement on the 08 September 2017 during night-time, with the southern hemisphere mid-latitude TEC increase extending to daytime. What could be the causes of this profound night-time electron density enhancement? To partly answer this question, Figure 8(a) shows the equatorial electric field (EEF) from the real-time prompt penetration electric field model [Manoj and Maus, 2012] at $30^{\circ} \mathrm{E}$ longitude, along with the IMF Bz for the 08 September 2017. In Figure 8(b), TEC perturbations for two conjugate locations (HRAO, South Africa and TUBI, Turkey) are shown to simply demonstrate the response levels in the two mid-latitude hemispheres. While IMF Bz is characterised by significant fluctuations on 08 September 2017 during the first two hours, it is largely negative. Both the background ( $E_{o}$, blue curve) and total electric field ( $E_{o}+E_{p}$, red curve) are negative, although the contribu- 


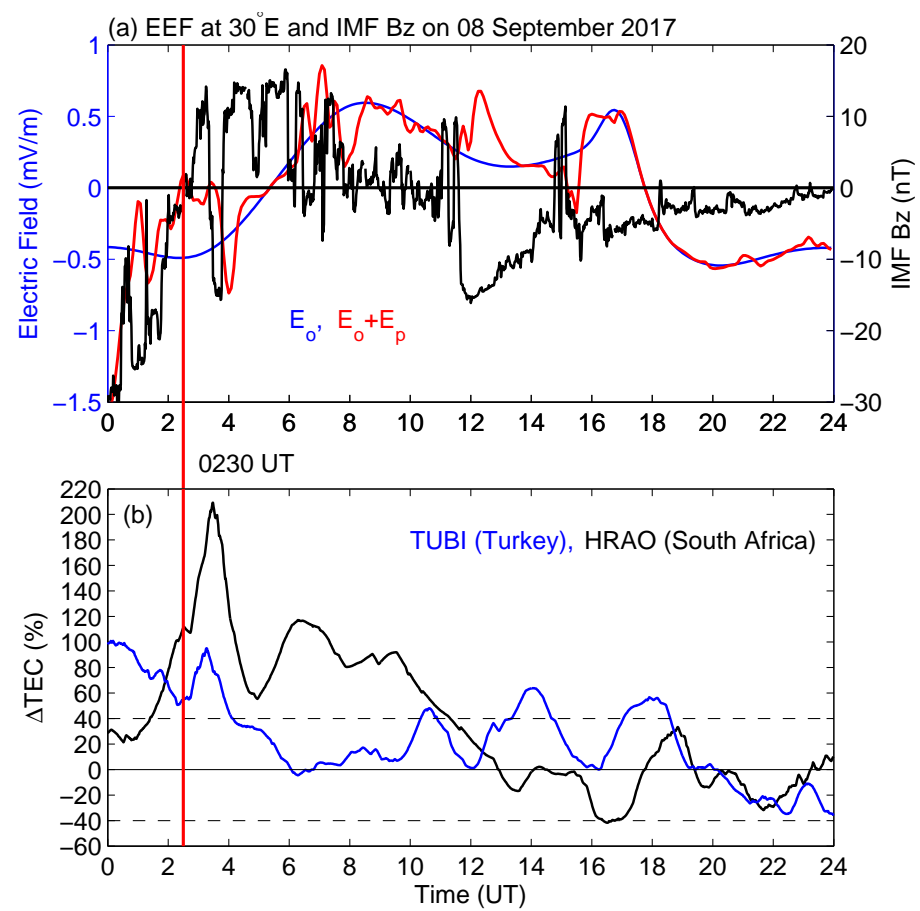

Figure 8. Equatorial electric field (EFF) at $30^{\circ} \mathrm{E}$ and IMF Bz; and $\triangle \mathrm{TEC}$ changes over conjugate locations HRAO (South Africa) and TUBI (Turkey) for 08 September 2017. In (a), $E_{o}$ and $E_{p}$ represent background and prompt penetration electric fields respectively.

tion of prompt penetrating electric field is evident to have started deviating from westward to eastward peaking at 0230 UT (see red straight line in Figure 8) which coincided with positive IMF Bz and followed by sharp increase in TEC over TUBI (blue curve) and HRAO (black curve). Maxima $\triangle \mathrm{TEC}$ of $210 \%$ and $95 \%$ are reached at $0328 \mathrm{UT}$ and 0316 UT for HRAO and TUBI respectively. For the short duration of positive IMF Bz starting from $0230 \mathrm{UT}$ (reaching maximum of $14 \mathrm{nT}$ at $0325 \mathrm{UT}$ ), we see sustained increase in TEC in both northern and southern hemispheres. The change of IMF Bz orientation from positive to negative reaching $-15.7 \mathrm{nT}$ at $0344 \mathrm{UT}$ is followed by a sudden drop in $E_{o}+E_{p}$ to $-0.74 \mathrm{mV} / \mathrm{m}(0400 \mathrm{UT}$ ) and $\Delta \mathrm{TEC}$ (from $210 \%$ to $55 \%$ at 0457 UT) for HRAO. It therefore appears that low/equatorial region processes have some influence on TEC variability in mid latitudes during the period (0300-0900 UT) of significant TEC increase on 08 September 2017. Background equatorial electric field is eastward (positive) and westward (negative) during local day and night-time respectively. During storms, southward IMF Bz can lead to penetrating electric field of magnetospheric 
origin to low/equatorial latitudes which is eastward and westward during day and nighttime respectively [Kelley et al., 1979; Scherliess and Fejer, 1997; Huang, 2008]. When the IMF Bz changes polarity from southward (negative) to northward (positive), the westward electric field reverses to eastward during nighttime. Although we do not have data to conclusively investigate the ionospheric current system over the region of study, magnetometer data showed increased ionospheric currents in the first hours of 08 September 2017 over Mbour $\left(14.39^{\circ} \mathrm{N}, 16.96^{\circ} \mathrm{W} ; 2.06^{\circ} \mathrm{N}\right.$ magnetic) which has local time difference of about 3 hours from our longitude sector [Imtiaz et al., 2020]. The reversal of prompt penetration electric field from westward to eastward during night time combined with the already existing eastward disturbance dynamo electric field can lead to strong vertical $\mathbf{E} \times \mathbf{B}$ drift over low latitudes. The consequence of this is that ionospheric plasma is lifted to higher altitudes with lower recombination processes and could lead to increased integrated electron content, which seems consistent with observations in Figure 8 starting from 0230-0400 UT. During local day-time, increased eastward electric field (as shown in Figure 8(a) from 0600-1200 UT with exception of a decrease within 0700-0800 UT) translates into enhanced vertical drift leading to electron density enhancements that have significant effects on the formation/expansion of the EIA. The EIA expansion will then lead to increase in TEC as far as mid-latitude regions. This is one of the possible causes of the increased TEC on 08 September 2017 during 0600-1200 UT. To confirm the role of the EIA expansion towards mid-latitudes, Figure 9 shows TEC from Global Ionospheric Maps (GIM) for 0400, 0600, 0800 and 1000 UT on 08 September 2017. The vertical red lines show the $10-40^{\circ} \mathrm{E}$ longitude sector covering data used for conjugate analysis within latitude ranges of $\sim 20-35^{\circ} \mathrm{S}$ and $\sim 40-50^{\circ} \mathrm{N}$.

In Figure 9(a), an increase in TEC is already visible at 0400 UT in southern hemisphere which is absent at similar latitudes in the northern hemisphere. Taking local time into account, this may not only be attributed to the photoionization effect given that the local time is the same, and therefore has to do with the storm induced processes. By 1000 UT (Figure 9(d)), the EIA has fully expanded as far as $40^{\circ} \mathrm{S}$ magnetic latitude and is prominent in the southern hemisphere. This confirms the higher levels of positive storm effect observed at MU12K $\left(33.2^{\circ} \mathrm{S}\right.$, magnetic latitude) compared to other ionosonde locations. Corresponding TEC increase is observed in the northern hemisphere, although with relatively smaller TEC magnitudes. In summary, GIM TEC agrees with and supports observations of the conjugacy analysis, and consequently highlighting the role of 

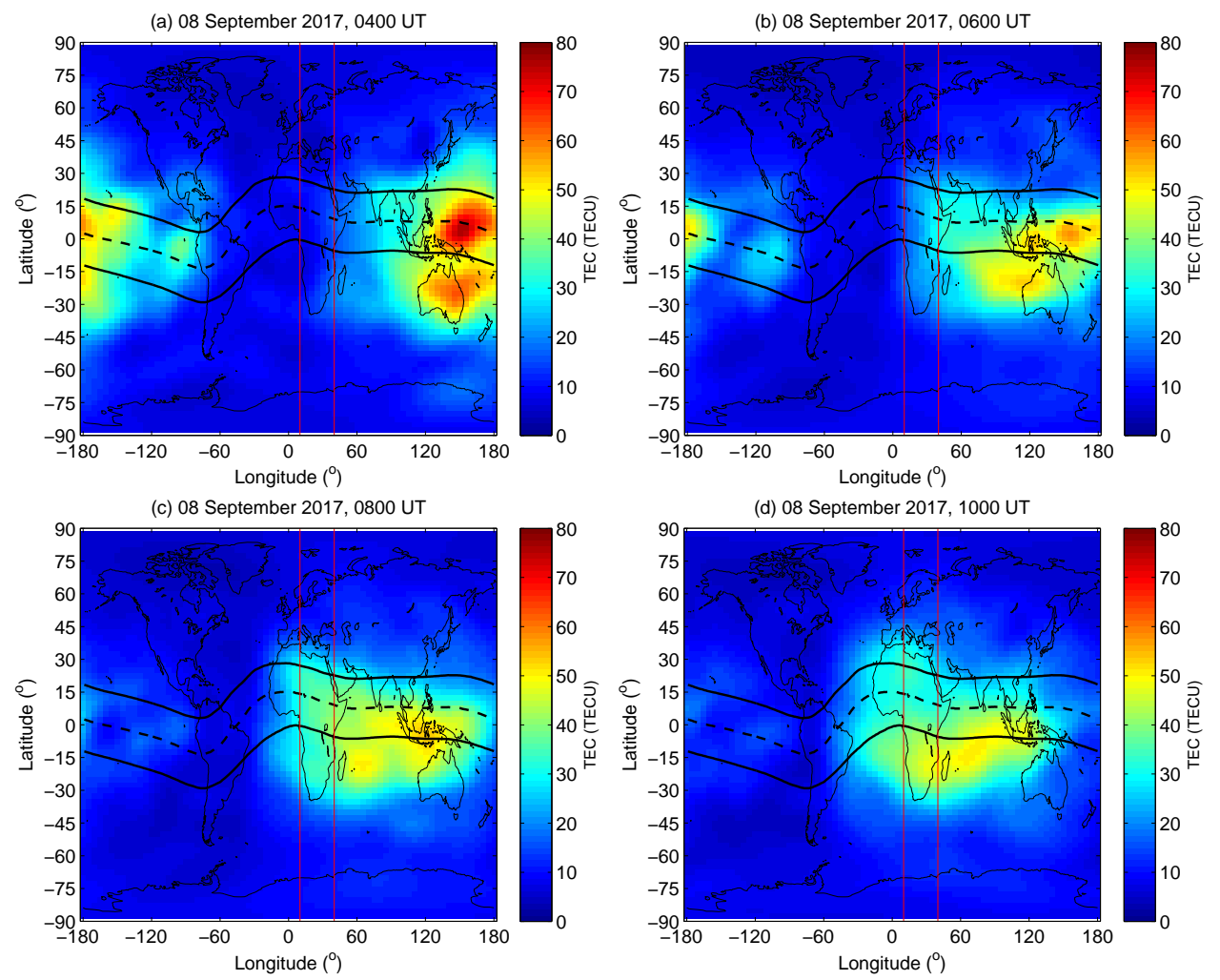

Figure 9. Global Ionospheric Maps (GIM) showing TEC for 0400 UT, 0600 UT, 0800 UT and 1000 UT on 08 September 2017. The vertical red lines show the $10-40^{\circ}$ E longitude sector covering data used for conjugate analysis for locations in Table 1. GIM data was downloaded from ftp://cddis.gsfc.nasa.gov/pub/gps/products/ionex/.

low latitude processes in influencing TEC in mid-latitudes on 08 September 2017. However, as earlier mentioned, we observe prolonged positive storm effect over southern hemisphere pointing to the existence of other physical mechanisms during this storm period. One such additional mechanism has been identified and shown as the existence of atmospheric gravity waves launched from high latitudes leading to the clearly more equatorward TID activity which extended from southern hemisphere latitudes into the northern hemisphere as shown in Figure 6(c). $\triangle$ TEC fluctuations related to TIDs' presence are apparent for almost the entire 08 September 2017 with the estimated velocity of 350 $\mathrm{m} / \mathrm{s}$. As mentioned earlier, increased $\mathrm{O} / \mathrm{N}_{2}$ ratio has been reported over the Europe-African mid and low latitudes for the 08 September 2017 compared to the quiet period of 05 September 2017 [Imtiaz et al., 2020], pointing to thermospheric composition changes as an ad- 
ditional contributor to the observed behavior in electron density or TEC within the 10$40^{\circ} \mathrm{E}$ longitude sector.

\section{Conclusions}

We have presented conjugate and regional analyses of ionospheric response during the geomagnetic storm of 07-08 September 2017 over the Europe-African mid latitude regions. Overall, it was found that electron density was enhanced over the European midlatitudes on 07 September 2017 while a corresponding feature or behavior was not observed in the southern hemisphere. On 08 September 2017, TEC showed a positive storm effect over both hemispheres with long-duration enhancements over Southern Africa lasting over 8 hours. The magnitude of the response in the southern hemisphere was at-least twice the derived percentage increase in the northern hemisphere when quantified based on the monthly median values. A combination of large scale TIDs, thermospheric composition changes and expansion of equatorial ionization anomaly were all found to be present during the duration of the positive storm effect in the southern hemisphere. The positive storm effect over PQ052 (northern hemisphere mid latitude) was only revealed by GPS TEC data, and a further analysis of ionosonde derived TEC up to the hmF2 peak and electron density variations from SWARM satellite showed that the topside and plasmasphere electron content was responsible. Consequently, it was shown that bottomside ionosphere contributed more (less) electron concentration on 08 September 2017 to the overall TEC in the southern (northern) hemisphere mid-latitudes, and thus the positive and negative storm effects shown by ionosonde foF 2 over the two respective hemispheres. This study has furthered the understanding of relative contributions at varying altitudes to TEC and highlighted the relative roles of competing/opposing mechanisms in midlatitudes within the two hemispheres. Thus, through a multi-dataset examination of hemispheric differences, we have simultaneously confirmed some of the previously observed features and associated physical mechanisms during geomagnetic storms.

\section{Acknowledgments}

This work is based on the research supported in part by the National Research Foundation of South Africa (Grant Numbers 112090 and 105778) and opinions, findings and conclusions or recommendations expressed in this paper are of the author(s), and the 
NRF accepts no liability whatsoever in this regard. The GNSS observations are provided by the University Navstar Consortium, UNAVCO (ftp://data-out.unavco.org) and South African National Geospatial Information (ftp://ftp.trignet.co.za). Global Ionospheric Map products in IONEX format are available at ftp://cddis.gsfc.nasa.gov/pub/gps/products/ionex/; and the JPL's maps were used. We acknowledge the OMNI dataset providers for compiling and making solar wind, AE and SYM-H index data available together (omniweb.gsfc.nasa.gov). AE and SYM-H data is also accessible from the World Data Center for Geomagnetism, Kyoto (http://wdc.kugi.kyoto-u.ac.jp). JBH thanks the ISSI-Bern International Team of "Why Ionospheric Dynamics and Structure Behave Differently in The African Sector?" (the team leaders E. Yizengaw and K. Groves) for valuable discussion about part of the results that are included in this paper.

\section{References}

Aa, E., W. Huang, S. Liu, A. J. Ridley, S. Zou, L. Shi, Y. Chen, H. Shen, and T. Wang (2019), Midlatitude plasma bubbles over China and adjacent areas during a magnetic storm on 8 September 2017, Space Weather, 16, 321-331, doi: 10.1029/2011JA017238.

Baker, K. B., and S. Wing (1989), A new magnetic coordinate system for conjugate studies at high latitudes, J. Geophys. Res., 94 (A7), 9139-9143, https://doi.org/10.1029/JA094iA07p09139.

Blagoveshchensky, D. V., and M. A. Sergeeva (2019), Impact of geomagnetic storm of September 7-8, 2017 on ionosphere and HF propagation: A multi-instrument study, Adv. Space Res., 63, 239-256, https://doi.org/10.1016/j.asr.2018.07.016.

Blagoveshchensky, D. V., M. A. Sergeeva, and P. C. Corona-Romero (2019), Features of the magnetic disturbance on September 7-8, 2017 by geophysical data, Adv. Space Res., 64, 171-182, https://doi.org/10.1016/j.asr.2019.03.037.

Borries, C., A. M. Mahrous, N. M. Ellahouny and R. Badeke (2016), Multiple ionospheric perturbations during the Saint Patricks Day storm 2015 in the European-African sector, J. Geophys. Res. Space Physics, 121 (11), 11333-11345, https://doi.org/10.1002/2016JA023178.

Buonsanto, M. J. (1999), Ionospheric storms - A review, Space Sci. Rev., 88, 563601. 
Buresova, D., J. Lastovicka, P. Hejda, and J. Bochnicek (2014), Ionospheric disturbances under low solar activity conditions, Adv. Space Res., 54(2), 185-196, doi:10.1016/j.asr.2014.04.007.

Cander, L. R. (2018), Ionospheric Space Weather, Springer Geophysics, 265-279.

Cherniak, I. V., I. E. Zakharenkova, A. Krankowski and I. I. Shagimuratov (2012), Plasmaspheric electron content derived from GPS TEC and FORMOSAT3/COSMIC measurements: Solar minimum condition, Adv. Space Res., 50, 427440.

Curto, J. J., S. Marsal, E. Blanch, and D. Altadill (2018), Analysis of the solar flare effects of 6 September 2017 in the ionosphere and in the Earth's magnetic field using spherical elementary current systems, Space Weather, 16, 1709-1720, doi:https://doi.org/10.1029/2018SW001927.

Danilov, A. (2001), F2-region response to geomagnetic disturbances, J. Atmos. Sol. Terr. Phys., 63 (5), 441-449.

Ding, F., W. Wan, B. Ning and M. Wang (2007), Large-scale traveling ionospheric disturbances observed by GPS total electron content during the magnetic storm of 29-30 October 2003, J. Geophys. Res. Space Physics, 112(A06309), https://doi.org/10.1029/2006JA012013

Habarulema, J. B., and S. A. Carelse (2016), Long-term analysis between radio occultation and ionosonde peak electron density and height during geomagnetic storms, Geophys. Res. Lett., 43, 4106-4111, doi:10.1002/2016GL068944.

Huang, C. S. (2008), Continuous penetration of the interplanetary electric field to the equatorial ionosphere over eight hours during intense geomagnetic storms, $J$. Geophys. Res., 113, A11,305, doi:10.1029/2008JA013588.

Huang, X., and B. W. Reinisch (1996), Vertical electron density profiles from the digisonde network, Adv. Space Res., 18, 121-129.

Jimoh, O., J. Lei, J. Zhong, C. Owolabi, X. Luan and X. Dou (2019), Topside Ionospheric Conditions During the 7-8 September 2017 Geomagnetic Storm, J. Geophys. Res. Space Physics, 124(11), 9381-9404.

Mendillo, M. (2006), Storms in the ionosphere: Patterns and processes for total electron content, Rev. Geophys., 44 (RG4001), doi:10.1029/2005RG000193.

Imtiaz, N., W. Younas, and M. Khan (2020), Response of the low- to mid-latitude ionosphere to the geomagnetic storm of September 2017, Ann. Geophys., 38, 359- 
372, https://doi.org/10.5194/angeo-38-359-2020.

Kelley, M. C., B. G. Fejer and C. A. Gonzalez (1979), An explanation for anomalous equatorial ionospheric electric field associated with a northward turning of the interplanetary magnetic field, Geophy. Res. Lett., 6, 301-304.

Lei, J., F. Huang, X. Chen, J. Zhong, D. Ren, W. Wang, et al. (2018), Was magnetic storm the only driver of the long-duration enhancements of daytime total electron content in the Asian-Australian sector between 7 and 12 September 2017?, J. Geophys. Res. Space Physics, 123, 3217-3232, https://doi.org/10.1029/2017JA025166.

Li, W., J. Yue, Y. Yang, C. He, A. Hu and K. Zhang (2018), Ionospheric and thermospheric responses to the recent strong solar flares on 6 September 2017, J. Geophys. Res. Space Physics, 123, https://doi.org/10.1029/ 2018JA025700.

Lotz, S. I., and M. Clilverd (2019), Demonstrating the Use of a Class of MinMax Smoothers for D Region Event Detection in Narrow Band VLF Phase, Radio Science, 54(3), 233-244.

Manoj, C., and S. Maus (2012), A real-time forecast service for the ionospheric equatorial zonal electric field, Space Weather, 10(S09002), doi:10.1029/2012SW000825.

Matamba, T. M., J. B. Habarulema, and L. A. Mckinnell (2015), Statistical analysis of the ionospheric response during geomagnetic storm conditions over South Africa using ionosonde and GPS data, Space Weather, 13, 536-547.

Mosna, Z., D. Kouba, P. K. Knizova, D. Buresova, J. Chum, et al. (2020), Ionospheric storm of September 2017 observed at ionospheric station Pruhonice, the Czech Republic, Adv. Space Res., 65(1), 115-128.

Ngwira, C. M., J. B. Habarulema, E. Astafyeva, E. Yizengaw, O. F. Jonah, G. Crowley, et al. (2019), Dynamic response of ionospheric plasma density to the geomagnetic storm of 22-23 June 2015, J. Geophys. Res., 124, 7123-7139.

Prölss, G. W. (1993), On explaining the local time variation of the ionospheric storm effects, Ann. Geophys., 11(1), 1-9.

Prölss, G. W. (1993), Ionospheric F-region storms, Handbook of Atmospheric Electrodynamics, Vol. II

Prölss, G. W. (1993), Physics of the Earth's space environment, Springler-Verlag, Berlin, Heidelberg. 
Scherliess, L., and B. G. Fejer (1997), Storm time dependence of equatorial disturbance dynamo zonal electric fields, Journal of Geophysical Research: Space Physics, 102(A11), 24,037-24,046, doi:10.1029/97JA02165.

Shepherd, S. G. (2014), Altitude-adjusted corrected geomagnetic coordinates: Definition and functional approximations, J. Geophys. Res., 119(9), 7501-7521, https://doi.org/10.1002/2014JA020264

Tsurutani, B., A. Mannucci, B. Iijima, M. A. Abdul, J. H. A. Sobral, et al. (2004), Global dayside ionospheric uplift and enhancement associated with interplanetary electric fields, J. Geophys. Res. Space Physics, 109(A8), https://doi.org/10.1029/2003JA010342.

Vijaya Lekshmi, D., N. Balan, S. Tulasi Ram, and J. Y. Liu (2011), Statistics of geomagnetic storms and ionospheric storms at low and mid latitudes in two solar cycles, J. Geophys. Res. Space Physics, 116(A11328), doi:10.1029/2011JA017042.

Wanliss, J. A., and K. M. Showalter (2006), High-resolution global storm index: Dst versus SYM-H, Journal of Geophysical Research: Space Physics, 111(A02202), doi:10.1029/2005JA011034.

Yasyukevich, Y., E. Astafyeva, A. Padokhin, V. Ivanova, S. Syrovatskii and A. Podlesnyi1 Liu (2018), The 6 September 2017 X-class solar flares and their impacts on the ionosphere, GNSS, and HF radio wave propagation, Space Weather, 16, 1013-1027, https://doi.org/10.1029/2018SW001932.

Yizengaw, E., M. B. Moldwin, D. Galvan, B. A. Iijima, A. Komjathy and A. J. Mannucci (2008), Global plasmaspheric TEC and its relative contribution to GPS TEC, J. Atmos. Solar-Terr. Phys., 70, 1541-1548.

Yizengaw, E., M. B. Moldwin, P. L. Dyson, and T. J. Immel (2005), Southern Hemisphere ionosphere and plasmasphere response to the interplanetary shock event of 29-31 October 2003, J. Geophys. Res., 110(A09S30), doi:10.1029/2004JA010920.

Yuan, L., S. Jin, and A. Calabia (2019), Distinct thermospheric mass density variations following the September 2017 geomagnetic storm from GRACE and Swarm, J. Atmos. Solar-Terr. Phys., 184, 30-36.

Zakharenkova, I., E. Astafyeva, and I. Cherniak (2016), GPS and GLONASS observations of large-scale traveling ionospheric disturbances during the 2015 St. Patrick's Day storm, J. Geophys. Res., 121, 12138-12156. 